\title{
NOISE MAPPING FOR URBAN PART OF BANGALORE
}

\author{
Lakshmi $C^{1}$, Manjunath H. $N^{2}$, Bhavya G. $S^{3}$, Rashmitha Shankar $S^{4}$, Deekshitha $O^{5}$, Avinash Singh ${ }^{6}$ \\ ${ }^{1}$ Associate Professor, Department of Civil Engineering, S.J.B Institute of Technology, \\ Bangalore-560060, Karnataka, India \\ ${ }^{2}$ Associate Professor, Department of Civil Engineering, S.J.B Institute of Technology, \\ Bangalore-560060, Karnataka, India \\ ${ }^{3}$ Department of Civil Engineering, S.J.B Institute of Technology, Bangalore-560060, Karnataka, India \\ ${ }^{4}$ Department of Civil Engineering, S.J.B Institute of Technology, Bangalore-560060, Karnataka, India \\ ${ }^{5}$ Department of Civil Engineering, S.J.B Institute of Technology, Bangalore-560060, Karnataka, India \\ ${ }^{6}$ Department of Civil Engineering, S.J.B Institute of Technology, Bangalore-560060, Karnataka, India
}

\begin{abstract}
The most unbearable environmental pollutant in the present day condition is the noise. It is definitely an unwanted sound. In the present day, noise levels have gone up in almost all the places, which are proved as health hazard, causing harmful physical and physiological problems. The survey area covers a distance of 2.6Kms around the periphery of Rajajinagar (West of Chord road. The selected area was covered by locating 11 stations. Noise level measurements were made at respective stations. The sound level readings were recorded for twenty eight days. During day time survey was conducted from morning 6AM to 6PM. (for 10 minutes at each location). The noise measurements were carried out using noise measuring meter model IEC 651 TYPE II. This aimed at generating noise maps using GIS and GPS. Arc GIS software is used to generate map representing the noise levels. The noise pollution can be reduced by several methods such as by diversion of traffic flow, control of speed breakers, banning of horns, plantation of tree and also some legal measures to avoid further worsening of problems.
\end{abstract}

Keywords: noise levels, noise measuring meter, noise mapping, ARCMAP, noise pollution level

\section{INTRODUCTION}

Noise is a word used to describe which humans consider to contain little information or which they actually find unpleasant. The word "noise" is derived from the Latin word "nausea", meaning seasickness. Noise is among the most pervasive pollutants today. Noise from road traffic, jet planes, construction equipment, manufacturing processes, irrigation pumps, loud speakers, etc are audible litter that broadcast into the air, which breaks the silence of the environment.

Noise is the general word used to refer to unmusical, confused or inharmonious loud sounds, which are unpleasant or unexpected. The origin of noise is in human activities or as a part of environmental phenomena.

The World Health Organization (WHO) has brought out a document named as "Community noise" in assessing the noise-inducted effects, the global criterion is human health. The established definition of WHO says "health is a state of complete physical, mental and social well being and not merely the absence of the disease of infirmity". This is a wide conceptualization, which explicitly covers impacts of such disturbance and impairment of human activities and related annoyance reactions.

Almost all noise effects are undesirable, yet in many cases a conscious decision needs to be taken for prescribing the standards. As per the "The Noise Pollution (Regulation and Control) Rules, 2000" based on land use category a city or town has been classified into four zones or areas. Industrial zone, Commercial zone, Residential zone and Silent zone.

\section{OBJECTIVES}

Main objectives of the present study are:

- To measure the noise levels in the chosen areas from urban districts of Bangalore.

- To compare existing noise levels with standards to assess noise pollution in the chosen areas.

- To locate the problematic areas having noise levels higher than prescribed limits.

- To provide recommendations for preventing and controlling the noise pollution.

- $\quad$ To apply GIS and GPS techniques for analyzing noise measurements.

\section{SCOPE OF THE STUDY}

Bangalore is the fastest growing city in Asia. The rapid urbanization and industrialization of Bangalore city have increased the human population, industries and vehicular population, which are the major source of noise. The noises from the automobiles are a big concern now, as it is affecting the human life. The sampling stations for noise measurements were selected in urban areas of Bangalore. This is to know the prevailing noise levels for determining:

- It helps in zoning of areas, for development of cities.

- It checks the noise effect that causes health disorders.

- As noise is the first air pollutant, it helps in control of further pollution of noise and air. 


\section{FIELD STUDIES}

The significant increase in urban population, due to the growth of industrial and commercial activities has resulted in the city roads getting over crowded with vehicular traffic. The result of this is the increase in noise levels causing noise pollution, affecting the environment and the human beings in general.

The Noise pollution regulation and control rule has stringent noise level standards prescribed for the different zones. Since the growth of the city was fast and uneven, several zones are entrapped in one another causing noise pollution a big threat to each one of these zones.

Noise levels were recorded at eleven locations covering a periphery of about 2.6 kilometers in Rajajinagar (WOC). This is to conduct a detailed study on the extent of city traffic is responsible in causing a noise pollution.

This problem consists of:

- Collecting the data on noise levels in the urban part of Bangalore, categorized under different zones.

- Providing recommendations for future changes.

- Assessing probable factors contributing to the prevailing noise levels.

- Providing data for further corrective and remedial measures.

- Planning for future is assisted to overcome the existing problems.

\section{SAMPLING STATIONS}

The sampling stations are;

- S1 - Hosahalli Metro Station

- $\quad$ S2 - Shanimahatma Temple

- S3 - ASC College

- S4 - Choultry

- S5 - Fire Station

- $\quad$ S6 - Sidvin Hospital

- $\quad$ S7 - Girias

- $\quad$ S8 - Lewa School

- $\quad$ S9 - Variar Bakery

- $\quad$ S10 - Nandini Restaurant

- $\quad$ S11 - Park

\section{MEASUREMENT AND RECORDING OF}

\section{DATA}

The noise levels were measured from 29-Jan-2017 to 25Feb-2017. In all four week samples were collected at each sampling station during the day time from morning 6AM to 6PM. At all sampling stations 10 minutes were spent to record the sound level. To complete each cycle connecting all eleven locations the time taken was approximately 2 to 3 hours depending on the peak and non peak hour traffic. The noise levels were recorded continuously to obtain maximum noise level and minimum noise levels.

\section{SPECIMEN CALCULATIONS}

Specimen calculations based on readings taken at Sampling Station S1 -Hosahalli Metro station on Wednesday, 1-Feb2017 at 06:00 AM are shown. The set of readings that constitute the base data are shown below;

\subsection{Equivalent Sound Level $\left(L_{e q}\right)$}

Equivalent sound level can be defined as the constant noise level over a given time period that produces the same amount of -weighted energy as fluctuating level over the same time frame.

$$
L_{e q}=10 \log _{10} \sum_{i=1}^{i=n} f_{i} 10 \frac{l_{i}}{10}
$$

Where,

$f_{i}$ is the fraction of time the constant level

$\mathrm{l}_{\mathrm{i}}$ is present.

For the set of readings above, $\mathrm{f}_{\mathrm{i}}$ is taken as:

The formula for $\mathrm{L}_{\mathrm{eq}}$ translates to:

$$
L_{e q}=10 \log _{10}\left[\frac{1}{T} \int_{0}^{t} \frac{P_{t}^{2}}{P_{0}^{2}} d t\right]
$$

Where,

$\mathrm{T}=$ time period over which Leq is measured.

$\mathrm{P}_{\mathrm{t}}=$ instantaneous A weighted sound pressure.

$\mathrm{P}_{\mathrm{o}}=$ reference sound pressure $20 \mu \mathrm{pa}$.

\subsection{Noise Pollution Levels $\left(L_{N P}\right)$}

It was found by researchers that $\mathrm{L}_{\mathrm{eq}}$, the equivalent continuous sound levels on an energy basis, was an insufficient descriptor of the annoyance caused by fluctuating noise. Robinson included another noise pollution level NPL or $\mathrm{L}_{\mathrm{NP}}$, which he defined as:

$$
\mathrm{L}_{\mathrm{np}}=\mathrm{L}_{\mathrm{eq}}+\mathrm{K} \sigma
$$

Where,

$\mathrm{L}_{\mathrm{np}}=$ noise pollution level,

$\mathrm{L}_{\mathrm{eq}}=$ equivalent sound level,

$\mathrm{K}=$ constant $=2.56$ and

$\sigma=$ Standard deviation of the sound levels.

For the chosen specimen data set, the formula translates to:

$\mathrm{L}_{\mathrm{np}}=73.5+2.56 \times 4.54=85.12$ (rounded)

Where, $\sigma=4.54$ is the Standard Deviation of $\mathrm{L}_{\mathrm{eq}}$ for all the morning readings and

$\mathrm{L}_{\mathrm{EQN}}=73.5$ in the morning.

\section{ANALYSIS AND DISCUSSIONS}

The study provides:

- Measurements of noise levels in the chosen areas from urban districts of Bangalore.

- Comparison of existing noise levels with standards and an assessment of the noise pollution in the chosen areas. 
- Location of problematic areas having noise levels higher than prescribed limits.

- Recommendations for preventing and controlling the noise pollution

Analysis and discussions related to data recorded at Sampling Station S1-Hosahalli Metro station are detailed in this paper. The detailed report deals with analysis and discussions related to the above for each sampling station, followed by the respective graphs and tables. In the parameters used and their description are:

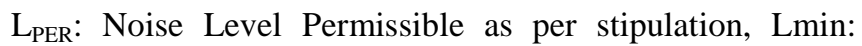
Minimum noise levels;

Lmax: Maximum noise levels

Leqn: Equivalent sound pressure level for Night; $\mathrm{L}_{\mathrm{NP}}$ : Noise Pollution Level for the day.

\subsection{Station S1 -Hosahalli Metro station}

Hosahalli Metro station is a commercial zone. It is a hub of commercial activities. The station is always crowded with heavy vehicles to lighter vehicles.

Lmin. at this station was observed to be ranging from $58.1 \mathrm{~dB}$ to $72.3 \mathrm{~dB}$ during daytime. Lmax was observed to be 88.9 for daytime. Leqn values are ranging from $69.2 \mathrm{~dB}$ to $86.9 \mathrm{~dB}$. The Permissible Leq (equivalent sound level) is $65 \mathrm{~dB}$. Observed Leqn's at this station have always remained more than the permissible values allowed for the commercial zone.

LNP (Noise pollution level) was found to be as low as 74.4 $\mathrm{dB}$ to as high as $93.08 \mathrm{~dB}$. The metro is the solution to reduce the traffic flow and hence reduce the noise pollution too.

\section{CONCLUSION}

Noise is a social problem and takes its origin from social, political and cultural activities. Sampling stations were selected to give a clear representation of zones such as industrial, commercial, residential and silent zones. The periphery of the surveyed area measures upto about 2.6 kilometers. Since the data collection has been over a period of 28 days and covers general holidays, holidays for schools, working days for schools and commercial establishments, and during day, it can be concluded that the data samples are good from a statistical perspective. Given the wide variety of sampling stations selected, the results can be used as a good indication of the general noise levels across the city. The survey provides a good sample size that has provided statistical results and analysis that can be used for guiding control measures to be implemented to reduce the problems associated with noise pollution.

From the tabulated observations and the analysis, it can be concluded that noise levels in most of the areas have exceeded the stipulated noise levels for the corresponding zones. Spatial distribution of noise level was mapped using ARCMAP.

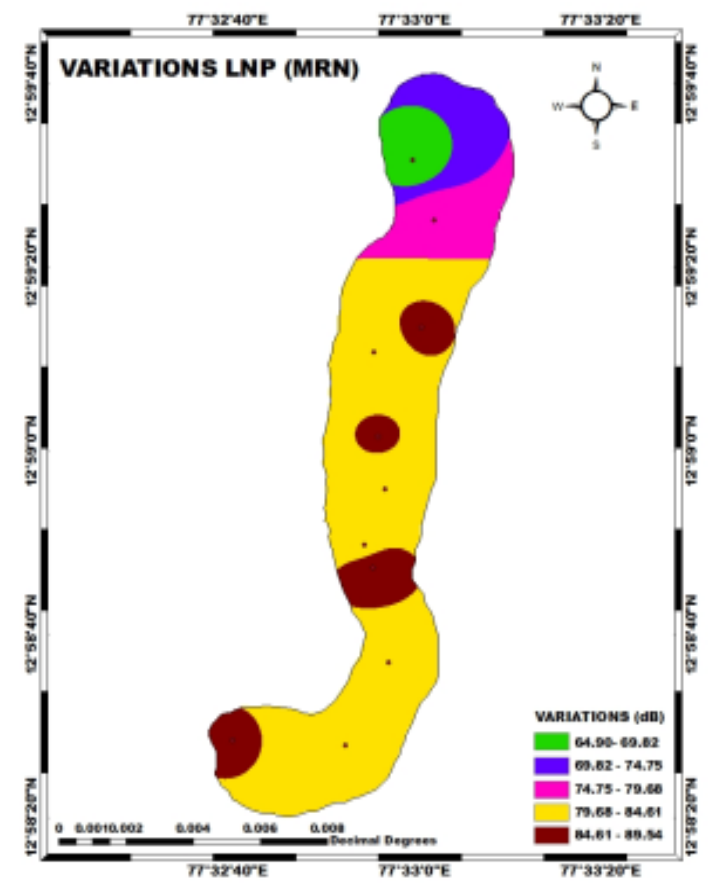

Fig.1: variation of Lnp (morning).

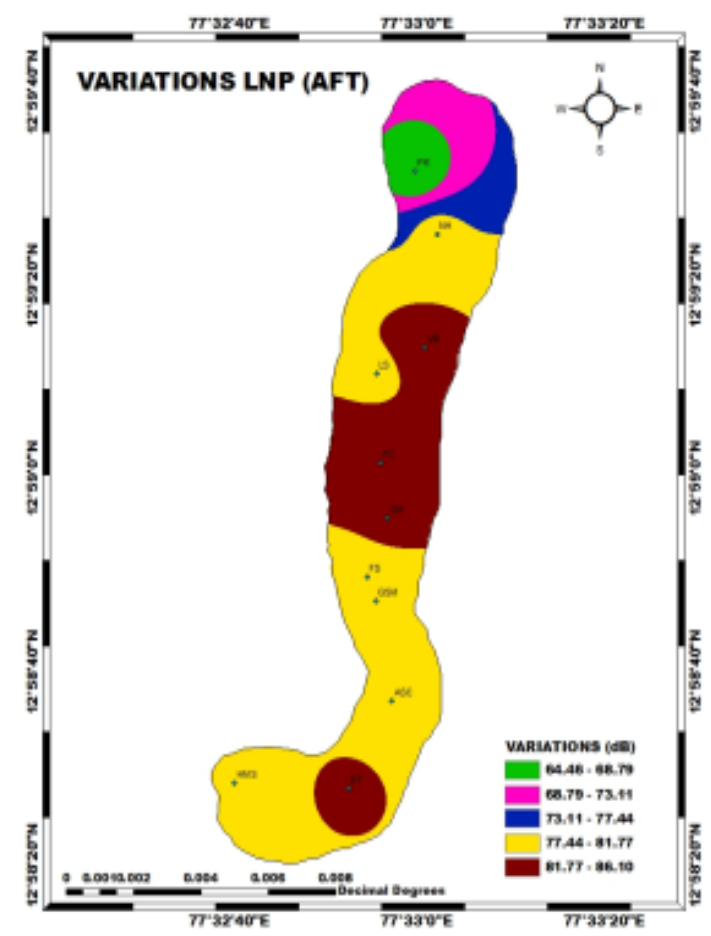

Fig. 2: variation of Lnp (afternoon). 


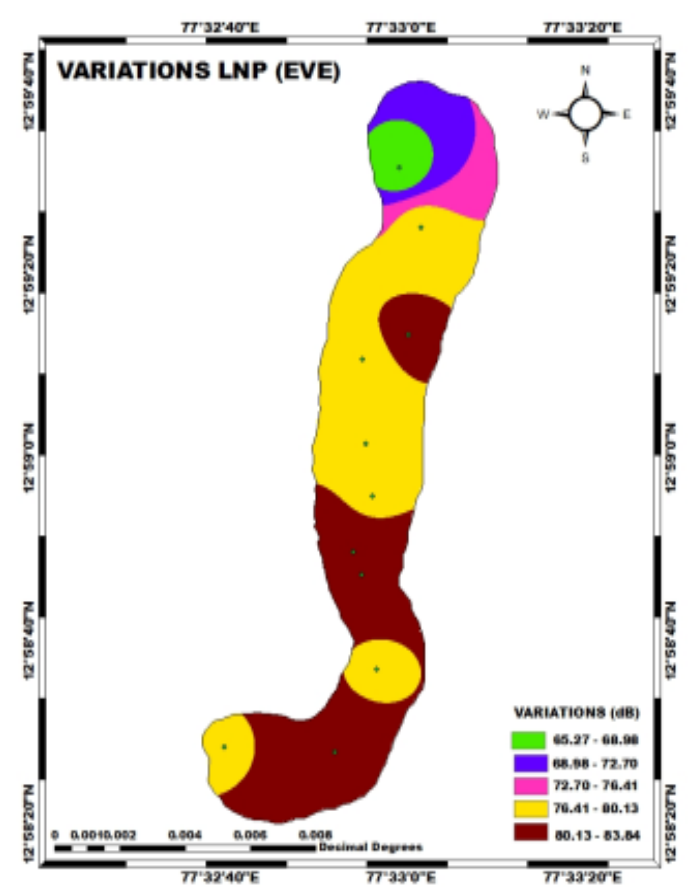

Fig. 3: variation of Lnp (evening).

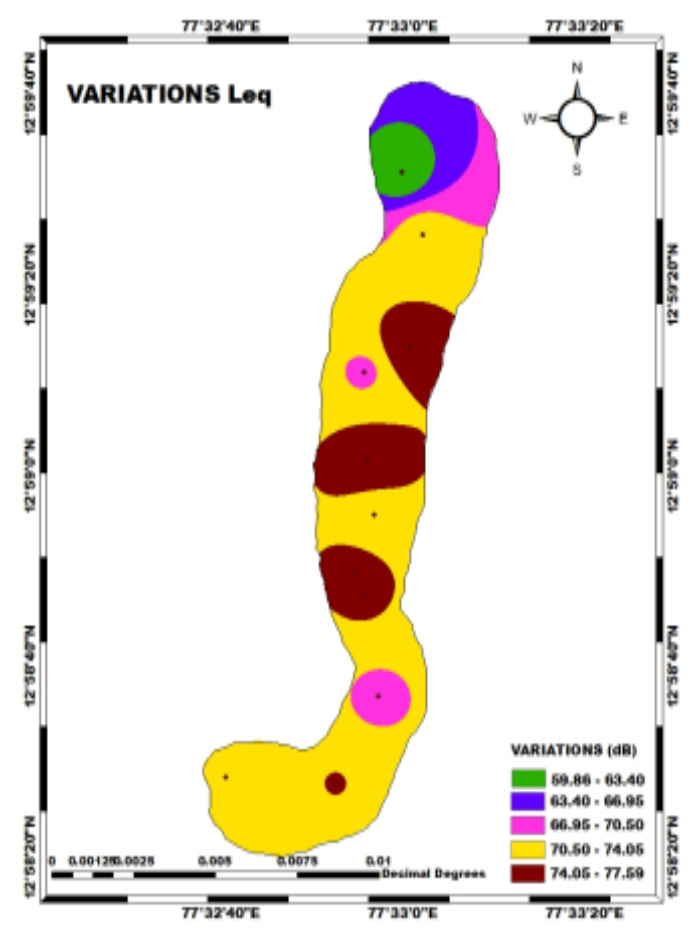

Fig. 4: variation of Leq.

\section{RECOMMENDATIONS}

Following are the various strategies which can be adopted for effective reduction of noise pollution in the chosen geographic area;

- Divert long distance traffic particularly heavy goods vehicles to an area clearly earmarked for such purpose thereby reducing the present suffering from the volume of traffic.

- People accessing metro facilities will reasonable reduce the noise levels.
- Close coordination between local planning authorities and highway authorities

- Locate and design hospitals, schools etc., to be away from the high traffic density zones so that they are not exposed to excessive or unacceptable levels of traffic noise.

- Use barriers or insulation techniques to reduce the effects of noise.

- Adopting vertical garden system on the road divider by growing creeper.

- Channelize traffic to relieve minor residential roads from heavy traffic.

- Plan major roads through areas where a high noise level already exists and thus an increase would not matter.

- The pavement must be maintained in all seasons without potholes,etc.

- Legal punishment must be enforced by law for negligence of civic sense, unnecessary honking, over speeding, etc.

\section{REFERENCES}

[1] The central Motor Vehicles Rules, 1989-(PART2) (2000); Karnataka Law Journal PublicationBangalore

[2] Bjorkman. M and Rylander R (1997); Maximum noise levels in city traffic; Journal of Sound and Vibrations.

[3] Noise pollution; Conference on environmental studies; Centre for Urban and Environmental studies Lucknow.

[4] Noise Level in Metropolitan Cities; Bangalore; Central Pollution Control Board, Delhi.

[5] Central Pollution Control Board (C.P.C.B) Manual, 1991.

[6] Law Library; "Noise references in the United states Code" enacted by U.S. Congress; Source Internet.

[7] The Air (prevention and control of pollution) Act, 1981(2000); Universal law publishing Co. Pvt. Ltd.

[8] Community Noise; A document published by world health organization.

[9] OSHA, Noise Control- A guide for workers and employers, US Department of Labour, Occupational Safety and Health Administration.

[10] Status of Noise In Peenya Industrial Area, Bangalore; Paper presented and published at 94thsession of ISC; Dr. B. Santhaveerana Goud, Dr Jayamma, Dr Nandini, Prof 